\title{
Effect of mother support groups on nutritional status in children under two years of age in Laisamis village, Kenya.
}

\author{
Mattias Undlien, Håvard-Amund Viervoll, Berit Rostad
}

Department of Public Health and General Practice, Faculty of Medicine, NTNU - Norwegian University of Science and Technology, Trondheim, Norway.

\begin{abstract}
Background: In tackling the ongoing malnutrition problem in many parts of Kenya, the government has initialized preventive actions such as mother support groups in order to improve health and nutrition among children. Few studies have evaluated the effectiveness of such intervention.

Objective: This study aimed at determining how mother support groups affect the nutrition status of children under 2 years of age.

Methods: 41 children participated. Anthropometric measurements were taken of the children once a month during 12 months. Medical history, nutrition status and socioeconomic factors were collected by interviews with the mothers. The children were divided into two groups depending on their mother's assigned group; mother support group or not.

Results: Nutritional status was significantly better among children in the mother support group $(\mathrm{P}=0.001)$. There were significantly more children with severe acute malnutrition among the children not in support group $(\mathrm{P}=0.040)$. The mean height $(\mathrm{P}=0.001)$ and mean weight $(\mathrm{P}=0.0281)$ were significantly higher among children in the non-support group.

Conclusion: Mother support groups may have a beneficial effect on the nutritional status of children under 2 years of age. Cases of severe acute malnutrition seemed to be less prevalent in children whose mothers attend mother support groups.

Keywords: Malnutrition, mother support groups, breastfeeding, Kenya.

DOI: http://dx.doi.org/10.4314/ahs.v16i4.4

Cite as: Undlien M, Viervoll H-A, Rostad B. Effect of mother support groups on nutritional status in children under two years of age in Laisamis village, Kenya. Afri Health Sci 2016;16(4): 904-909. http:/ / dx.doi.org/10.4314/ahs.v16i4.4
\end{abstract}

\section{Introduction}

Impaired nutrition is a major contributing factor to child morbidity, mortality and disability. ${ }^{1}$

Malnutrition is an underlying cause in more than $50 \%$ of all deaths among children, mostly due to increased susceptibility to and severity of common infectious diseases, often referred to as the malnutrition-infection complex. ${ }^{1}$ The importance of sufficient nutrition was recog-

\section{Corresponding author:}

Berit Rostad, Department of Public Health, and General Practice, Faculty of Medicine.

NTNU - Norwegian University of Science and Technology. 7489 Trondheim, Norway

Tel: $+4773598777 ;+4798408972$

Fax: +4773597577

E-mail: berit.rostad@ntnu.no nized in the Millennium Development Goals (MDG) and in the current Sustainable Development Goal number 2 , to end hunger and improve nutrition. ${ }^{2}$ Approximately one third of all deaths before the age of five is attributed to malnourishment. ${ }^{3}$ Infants are the most vulnerable as they require sufficient nutrition for growth and development, thus malnutrition in the first two years of life may have wide-ranging short term and long term health consequences, extending into adulthood. ${ }^{3}$ Despite succeeding in reducing child mortality in the world by nearly 50 $\%$, some areas of the world are still lagging behind. ${ }^{4}$

Kenya is among the countries with the highest child mortality rate in the world. ${ }^{5}$ The country did not meet the MDG number 1; to halve the proportion of underweight children. ${ }^{6}$ An annual health and nutrition survey in Laisamis sub-county from September 2015, "The Smart Study", showed that $32.7 \%$ of children $6-59$ months of age were underweight, that $25.9 \%$ were stunted and that $23.7 \%$ were wasted. ${ }^{7}$ The latter, reported as Global Acute 
Malnutrition (GAM), increased to $23.7 \%$ in September 2015 from a percentage of $18.2 \%$ in July $2014 .^{7}$ These discouraging numbers are attributed to chronic food insecurity due to erratic rainfall and prolonged dry spells, as well as sub-optimal child care and feeding practices. ${ }^{7}$ The latter factors have raised the need for nutrition surveillance, nutritional care as well as supplementary feeding programs for malnourished children.

Recent research has shown that breastfeeding is an optimal way of providing ideal nutrition in infants, for healthy growth and development. ${ }^{8}$ WHO recommends that all infants should be fed exclusively on breast milk from birth to 6 months of age. ${ }^{8}$ Implementing proper breastfeeding and complimentary feeding regiments are crucial to improving health and nutrition in young children, and such an intervention provides long-term health benefits for the rest of the lifespan. ${ }^{9}$ According to the 2008-09 Kenya Demographic and Health Survey, only $32 \%$ of Kenyan babies are exclusively breastfed to the age of six months. ${ }^{10}$

Mother Support Groups program (MSGs) is part of the national strategy of improving infant and young child nutrition in Kenya. Groups of women either pregnant or with children under 5 years of age learn about the importance of breastfeeding and adequate nutrition by means of health education, demonstrations and discussions. ${ }^{11}$ Further, the women support each other and share experiences aided by a trained experienced mother. The MSG is complementary to health services in improving mothering capabilities. The groups are closely linked with health facilities providing nutritional assistance. ${ }^{11}$ It is important to evaluate the effectiveness of these groups in order to ensure the best possible allocation of resources. To our knowledge, there are few studies on such interventions as the MSG program and its effect on improved nutrition status of children. Against this background, our study aimed at determining how MSGs affect the nutrition status of children under 2 years of age in Laisamis village, Kenya.

\section{Methods}

\section{Study center and population}

This descriptive comparative study was carried out at the out-patient and out-reach clinic at Laisamis Catholic Hospital, Kenya, from January 2015 until March 2016. The research was undertaken in cooperation with the clinic, which offers services to people living in Laisamis village.
The study population consisted of children less than 2 years of age in Laisamis, but enrolled in the study at the age of $\leq 6$ months and attending the clinic's nutrition center. Pregnant women and mothers with children under six months of age were invited to participate in the study. All women asked to participate accepted the invitation. The study population was divided into two groups; an intervention group consisting of children whose mothers participated in MSG, and a group of children whose mothers did not. Both groups got standardized treatment (including supplementary feeding if defined malnourished) and counselling.

The clinic nutritionist together with community health workers recruited the two groups by selecting women from two different parts of the village, thus the two groups were based on the area they lived. This was done so that the mothers easily could meet in their support group, as walking was the only affordable means of transportation. The support group met twice a month, headed by a peer mother, herself an experienced breastfeeding mother, to assist, inform and discuss with the mothers the importance of breastfeeding, childcare and nutrition (the latter by lectures from a nutritionist). The group was limited to 20 mothers, since MSGs optimal group size are 12 to 20 mothers. Additional 12 mothers were interviewed in order to provide additional background information on mothers benefiting from the nutrition center's services. Written consent was obtained from all participating mothers, upon written and verbal information about the study. The study was given ethical approval by the Regional Committee for Medical and Health Research Ethics, Norway and by Department of Health, County Government of Marsabit, Kenya.

\section{Study material and measures}

Interviews based on a structured questionnaire were used to obtain health, nutrition and socioeconomic information about the children and their families. The interviews were carried out with the children's mothers in February 2016. Every month from January 2015 to February 2016 nutritional status was assessed by measuring height, weight and mid upper arm circumference (MUAC) of the participating children. The children's height was measured lying down on a length board with a movable footboard. Weight was measured on a standard weighing scale. MUAC was measured with a tape measure. Recommended anthropometric indices as to WHO standard- 
ized references, were used to characterize malnutrition. Z-score was calculated based on the height and weight measurements. Moderate acute malnutrition (MAM) was defined as weight-for-height between -3 and -2 Z-scores, while severe acute malnutrition (SAM) was defined as Z-score cut-off-point of $<-3$ weight-for-height of the median WHO growth standards. ${ }^{12}$

\section{Data analysis}

Descriptive statistics of children and mothers stratified by attendance in MSG or not, are presented in numbers and percentages. The analysis of the data is corrected for time participating in the study. Differences between the groups were assessed by applying chi-squared test. Student's t-test was used to assess differences in mean weight, height, MUAC and Z-score. Statistical significance was set at $\mathrm{P}<0.05$. Analyses were performed using SPSS statistics (version 19, SPSS INC., Chicago, IL) and STATA (Release 14, StataCorp. 2015, College Station, TX: StataCorp LP).

\section{Results}

A total of 41 children constituted the two groups, 20 mothers in each group. Many of the study families were nomadic pastoralists, regularly traveling long distances to fresh pastures with their livestock. Thus, many were unreachable for parts of the study period. Because of this, only 31 of the mothers were available for interview at the end of the study period. Some of the mothers were in the grazing fields with their children for a few months during the study period, consequently some measurements are missing.

Table 1 presents socio-demographic characteristics of mothers in MSG, mothers not in support group and regular beneficiaries (other mothers) of nutritional services of Laisamis Catholic Hospital. There were more mothers under 25 years and fewer mothers between 25-30 years among the regular beneficiaries than in the two study groups. There were few differences in marital status, in fact only one mother in the non-support group reported being unmarried. Of mothers in all three groups, most $(72.1 \%)$ had no education (not shown in table). There was a somewhat higher proportion of mothers without any education in the MSG when compared to the other two groups. $60.5 \%$ of all mothers reported being housewives (not shown in table). Fewer of the mothers not in support group reported having manual work, when compared to the other two groups. In general, the fathers had more education than the mothers, and more of them were working; $38.1 \%$ were self-employed, $33.3 \%$ were nomadic pastoralists and $28.5 \%$ had other or no work as reported by the mothers (not shown in table). They further reported that $63.4 \%$ of fathers had some education (not shown in table).

Table 1: Socio-demographic characteristics of mothers attending the nutrition center

\begin{tabular}{|c|c|c|c|}
\hline Characteristics & $\begin{array}{l}\text { Other mothers } \\
\mathbf{N}(\%) \\
\end{array}$ & $\begin{array}{l}\text { Mothers in support } \\
\text { group } \\
\text { N }(\%) \\
\end{array}$ & $\begin{array}{l}\text { Mothers not in } \\
\text { support group } \\
\text { N }(\%) \\
\end{array}$ \\
\hline \multicolumn{4}{|l|}{ Age group } \\
\hline$<25$ & $6(50.0)$ & $4(28.5)$ & $6(35.3)$ \\
\hline $25-30$ & $2(16.7)$ & $5(35.7)$ & $6(35.3)$ \\
\hline$>30$ & $4(33.3)$ & $5(35.7)$ & $5(29.4)$ \\
\hline \multicolumn{4}{|l|}{ Married } \\
\hline Yes & $12(100.0)$ & $14(100.0)$ & $16(94.1)$ \\
\hline No & $0(0.0)$ & $0(0.0)$ & $1(5.9)$ \\
\hline \multicolumn{4}{|l|}{ Education } \\
\hline Education & $4(33.3)$ & $2(14.3)$ & $6(35.3)$ \\
\hline No education & $8(66.7)$ & $12(85.7)$ & $11(64.7)$ \\
\hline \multicolumn{4}{|l|}{ Occupation } \\
\hline Manual worker & $7(58.3)$ & $9(64.2)$ & $3(17.5)$ \\
\hline Housewife & $5(41.7)$ & $5(35.7)$ & $14(82.4)$ \\
\hline \multicolumn{4}{|l|}{ Health status } \\
\hline Good & $12(100.0)$ & $14(100.0)$ & $16(94.5)$ \\
\hline Fair & $\mathrm{O}(0.0)$ & $\mathrm{O}(0.0)$ & $1(5.8)$ \\
\hline
\end{tabular}


Table 2 shows differences in socio-demographic factors, health factors and nutritional status of the children in the two study groups. There were no substantial differences between the two groups of children in terms of age group, sex or number of siblings; however, the children not in support group lived in smaller households (see Table 2). There was no significant difference between the two groups in reported acute respiratory illness, diarrhoea or fever in the last two weeks prior to the final measurements in February. There was no significant difference between the two groups with respect to breastfeeding practices. Every mother in both groups said they had breastfed their child exclusively for the first 6 months. The mean height and mean weight were significantly higher among children in the non-support group compared to the children in the MSG. The nutritional status measured by the mean Z-score was significantly better among children in the MSG than in the non-support group. There was a non-significant higher number of children with Moderately Acute Malnutrition (MAM) among children not in support group compared to children in the MSG. There was a significant higher number of children with severe acute Malnutrition (SAM) among children not in support group compared to children in the MSG. There were no differences between the groups as regards to MUAC.

Table 2: Socio-demographic characteristics, health and nutritional status in children whose mothers are in support group and not in support group

\begin{tabular}{|c|c|c|c|}
\hline Characteristics & $\begin{array}{l}\text { Support group } \\
\text { N }(\%)\end{array}$ & $\begin{array}{l}\text { Not in support } \\
\text { group } N(\%)\end{array}$ & $\begin{array}{l}\mathbf{P} \\
\text { value } \\
\end{array}$ \\
\hline \multicolumn{4}{|l|}{ Age groups in months } \\
\hline $0-12$ & $10(50.0)$ & $9(42.8)$ & 0.647 \\
\hline$>12$ & $10(50.0)$ & $12(57.1)$ & \\
\hline \multicolumn{4}{|l|}{ Sex } \\
\hline Male & $9(45.0)$ & $12(57.1)$ & 0.437 \\
\hline Female & $11(55.0)$ & $9(42.8)$ & \\
\hline \multicolumn{4}{|l|}{ Household } \\
\hline Mean number of children (SD) * & $5.6(3.5) *$ & $3.7(2.5) *$ & 0.0862 \\
\hline Mean number of adults (SD) * & $1.93(0.61) *$ & $1.64(0.49) *$ & 0.167 \\
\hline \multicolumn{4}{|l|}{ Diseases last 2 weeks } \\
\hline Yes & $4(28.5)$ & $2(11.7)$ & 0.239 \\
\hline No & $10(71.4)$ & $15(88.2)$ & \\
\hline \multicolumn{4}{|l|}{ Fever } \\
\hline Yes & $8(57.1)$ & $6(35.3)$ & 0.224 \\
\hline No & $6(42.8)$ & $11(64.7)$ & \\
\hline \multicolumn{4}{|l|}{ Cough/Fast breathing (ARI) } \\
\hline Yes & $7(50.0)$ & $4(23.5)$ & 0.125 \\
\hline No & $7(50.0)$ & $13(76.4)$ & \\
\hline \multicolumn{4}{|l|}{$\begin{array}{l}\text { Nutrition status } \\
\text { Moderate Acute Malnutrition }\end{array}$} \\
\hline Yes & $5(25.0)$ & 9 (42.9) & 0.228 \\
\hline No & $15(75.0)$ & $12(57.1)$ & \\
\hline \multicolumn{4}{|l|}{ Severe Acute Malnutrition } \\
\hline Yes & $0(0.0)$ & $4(19.0)$ & 0.040 \\
\hline No & $20(100.0)$ & $17(81.0)$ & \\
\hline \multicolumn{4}{|l|}{ Breastfed first 6 months } \\
\hline Yes & $14(100.0)$ & $17(100.0)$ & 0.414 \\
\hline No & $0(0.0)$ & $0(0.0)$ & \\
\hline \multicolumn{4}{|l|}{ Measures } \\
\hline Mean Height (SD)* & $67(3.9) *$ & $70.5(4.3) *$ & 0.0001 \\
\hline Mean Weight (SD)* & $6.4(1.5) *$ & $6.8(1.8) *$ & 0.0281 \\
\hline Mean MUAC (SD)* & $13.6(0.78) *$ & $13.3(1.1) *$ & 0.0615 \\
\hline Mean Z-score (SD)** & $-0.39 * *(0.61)$ & $-0.83 * *(0.90)$ & 0.0001 \\
\hline
\end{tabular}

*Standard deviation

**Differences in means tested by Student's t-test 


\section{Discussion}

Our objective was to investigate if and how MSGs affected nutritional status in children under 2 years of age. Our findings suggest that MSGs can have a positive effect on the nutritional status in children less than two years of age. Our principal finding was that there might be fewer cases of severe acute malnutrition (SAM) among children of mothers participating in support groups.

To the best of our knowledge, this is the first attempt to determine any effect of MSGs implementation on nutrition in Kenya. We have not found any research on the relation between mother support group participation and influence on nutritional status in infants. Local health workers in Laisamis reported that they had the impression that the mothers' compliance with the treatment for malnourished children was better in the MSG than in the not support group. They reported instances where supplementary food and therapeutic nutritional supplements were shared with siblings and other family members, and not given to the malnourished child they were intended for. It was not unusual, they said, that mothers returned for more nutritional supplements shortly after receiving a week's supply, because they had shared supplies with the whole family. This may indicate that the mothers lacked proper guidance on nutrition and care for malnourished children. Unfortunately, we were not in a position to investigate differences in compliance between the groups. If the health workers' observations are correct, then differences in compliance might explain differences in nutritional status in the two groups. Children with mothers not in support group lived in smaller households, and this may explain their higher weight and height.

All mothers in the study agreed to participate in the study. Earlier studies of malnutrition in Marsabit County has concluded that social stigma connected with malnourished children is an important reason why mothers do not seek help for malnutrition. ${ }^{13}$ We did not investigate this in our study, but we may suggest that increased general awareness on nutrition initiated by the establishment of mother support groups might contribute to reduce the stigma, and as such lower the threshold for mothers to seek help at health care facilities.
The results show an apparent raised awareness of the importance of breastfeeding in both groups, as all mothers reported exclusive breastfeeding their children for 6 months regardless of participation in the support group or not. In Kenya only $32 \%$ of children are exclusively breastfed for 6 months. ${ }^{10}$ Our findings indicate the important supportive and informative role of health workers to improve breastfeeding practices. Lack of breastfeeding counseling is reported to be an important reason why mothers stop exclusive breastfeeding only a few weeks after delivery. ${ }^{14}$ Our study confirms earlier research indicating that mothers having knowledge of exclusive breastfeeding are less likely to end exclusive breastfeeding early. ${ }^{15}$ Earlier studies of mother support groups in India found a significant positive effect on breastfeeding practices among participants in support groups only. ${ }^{16}$ Our study found no such effects limited to mothers in support group. However, our study did not inquire into the number of feedings per day as the Indian study did. These methodological differences may possibly contribute to the diverse results. The improved nutrition status (measured as SAM) in children of mothers in support group may be explained by appropriate nutrition practices and proper care for malnourished children.

\section{Study limitations}

The study sample size is very limited, and all measurements are therefore subject to uncertainty. Thus, any results should be interpreted with extreme caution. The two groups in the study were not randomly assigned. Even though there seem to be few substantial differences in the socio-demographic and health factors we assessed, there were some differences. Due to the selection process by geography, there may be confounders we have not considered. Our research suggests that MSGs can be successful in improving nutritional outcomes in children less than two years of age. As such, our results may offer some encouragement to establishing MSG programs.

\section{Conclusion}

Our study suggests that Mother Support Groups might improve nutritional status, and the most notable finding was fewer cases of severe malnutrition in children under two years of age. All mothers in the study reported breastfeeding exclusively for 6 months, suggesting that general awareness of the importance of breastfeeding in itself leads to better breastfeeding practices. 


\section{Acknowledgements}

We would like to thank all the women and children who participated in this study. Further, thanks to county nutrition officer of Marsabit, Mr. James Kamotho, field assistant and nutritionist Martin Njue and nutritionist Mercy Busuru for their valuable assistance.

\section{Conflict of interest}

None to declare.

\section{References}

1. Lindstrand A, Bergström S, Rosling H, Rubenson B, Stenson B, Tylleskär H. Global Health, an introductory textbook. 1st ed. Denmark: Narayana Press, 2006.

2. WHO. Open Working Group Proposal for Sustainable Development Goals. Available at: https://sustainabledevelopment.un.org/focussdgs.html. Assessed May 12, 2016.

3. UNICEF. Improving Child Nutrition: The achievable imperative for global progress. 2013;6. Available at: http://data.unicef.org/resources/improving-child-nutrition-the-achievable-imperative-for-global-progress\#sthash.5DZ5Z1p4.dpuf. Assessed May 10, 2016.

4. United Nations Development Programme. The Millennium Development Goals Report 2014. 2014;24. Available at: http://www.undp.org/content/undp/en/ home /librarypage/mdg/ the-millennium-development-goals-report-2014.html. Assessed May 12, 2016.

5. UN Inter-agency Group for Child Mortality Estimation (IGME). Levels and Trends in Child Mortality. Report 2015. 2015;4. PubMed Available at:http://www. childmortality.org/files_v20/download/IGME\%20report $\% 202015 \% 20$ child $\% 20$ mortality $\% 20$ final.pdf. Assessed May 12, 2016.

6. United Nations Development Programme. Millennium Development Goals, Status Report for Kenya. Nairobi: Ministry of Devolution and Planning; 2013;5. Available at: http://www.undp.org/content/dam/undp/library/
MDG/english/MDG\%20Country\%20Reports/Kenya/ Kenya\%20MDG\%202014.pdf?download. Assessed May 9, 2016.

7. Ministry of Health. County Government of Marsabit. Laisamis SMART Survey Report September 2015. Marsabit: 2015.

8. WHO. Nutrition, Exclusive breastfeeding. Available at: http:/ /www.who.int/nutrition / topics / exclusive_breastfeeding/en/. Assessed May 10, 2016.

9. WHO. Essential Nutrition Actions, Improving maternal, newborn, infant and young child health and nutrition. 2013;2. Available at:http://www.who.int/nutrition/publications/infantfeeding/essential_nutrition_actions/en/. Assessed May 122016.

10. Kenya National Bureau of Statistics (KNBS) and ICF Macro. Kenya Demographic and Health Survey 2008-09. 2010:149. Available at: http://dhsprogram.com/pubs/ pdf/fr229/fr229. pdf. Assessed June 04, 2016.

11. WHO. The role of mother support groups. 1993. Available at: http://apps.who.int/iris/ bitstream/10665/58728/2/WHO_NUT_ MCH_93.1_\%28part2\%29.pdf. Assessed May 12, 2016. 12. UNICEF. Acute Malnutrition: Classification. Available at: http://www.unicef.org / nutrition /training/2.3/13. html. Assessed June 042016.

13. Bliss J, Njenga M, Stoltzfus R, Pelletier D. Stigma as a barrier to treatment for child acute malnutrition in Marsabit County, Kenya. Maternal \& Child Nutrition 2016,12(1): 125-138.

14. United Nations. UN agencies issue ten tips for successful breastfeeding; A mother-to-mother breastfeeding support group. 2010. Available at: http://search. proquest.com/printviewfile?accountid $=12870$. Assessed June 03, 2016.

15. Kushwaha KP, Sankar J, Sankar MJ, Gupta A, Dadhich JP, Gupta YP et. al. Effect of peer counselling by Mother Support Groups on infant and young child feeding practices: The Lalitpur experience. PloS one 2014;9(11):e109181. 